\title{
Provider use of a participatory decision-making style with youth and caregivers and satisfaction with pediatric asthma visits
}

This article was published in the following Dove Press journal: Patient Related Outcome Measures

\author{
Betsy Sleath ${ }^{1,2}$ \\ Delesha M Carpenter ${ }^{1}$ \\ Imelda Coyne ${ }^{3}$ \\ Scott A Davis' \\ Claire Hayes Watson' \\ Ceila E Loughlin ${ }^{4}$ \\ Nacire Garcia' \\ Daniel S Reuland ${ }^{5}$ \\ Gail E Tudor \\ 'Division of Pharmaceutical \\ Outcomes and Policy, UNC Eshelman \\ School of Pharmacy, University \\ of North Carolina at Chapel Hill, \\ Chapel Hill, NC, USA; ${ }^{2}$ Cecil G. \\ Sheps Center for Health Services \\ Research, University of North \\ Carolina at Chapel Hill, Chapel Hill, \\ NC, USA; ${ }^{3}$ School of Nursing and \\ Midwifery, Trinity College, Dublin, \\ Ireland; ${ }^{4}$ Department of Pediatric \\ Pulmonology, School of Medicine \\ University of North Carolina at \\ Chapel Hill, Chapel Hill, NC, USA; \\ ${ }^{5}$ Division of General Internal Medicine \\ and Clinical Epidemiology, School \\ of Medicine, University of North \\ Carolina at Chapel Hill, Chapel Hill, \\ NC, USA; 'Department of Science \\ and Mathematics, Husson University, \\ Bangor, ME, USA
}

Correspondence: Betsy Sleath

Division of Pharmaceutical Outcomes

and Policy, UNC Eshelman School of

Pharmacy, University of North Carolina

at Chapel Hill, CB\# 7573, Chapel Hill,

NC 27599-7573, USA

$\mathrm{Tel}+19199620079$

Fax + I 9199668486

Email betsy_sleath@unc.edu
Background: We conducted a randomized controlled trial to test the effectiveness of an asthma question prompt list with video intervention to engage the youth during clinic visits. We examined whether the intervention was associated with 1) providers including youth and caregiver inputs more into asthma treatment regimens, 2) youth and caregivers rating providers as using more of a participatory decision-making style, and 3) youth and caregivers being more satisfied with visits.

Methods: English- or Spanish-speaking youth aged 11-17 years with persistent asthma and their caregivers were recruited from four pediatric clinics and randomized to the intervention or usual care groups. The youth in the intervention group watched the video with their caregivers on an iPad and completed a one-page asthma question prompt list before their clinic visits. All visits were audiotaped. Generalized estimating equations were used to analyze the data.

Results: Forty providers and their patients $(n=359)$ participated in this study. Providers included youth input into the asthma management treatment regimens during $2.5 \%$ of visits and caregiver input during $3.3 \%$ of visits. The youth in the intervention group were significantly more likely to rate their providers as using more of a participatory decision-making style (odds ratio $=1.7,95 \%$ confidence interval $=1.1,2.5$ ). White caregivers were significantly more likely to rate the providers as more participatory (odds ratio $=2.3,95 \%$ confidence interval $=1.2,4.4$ ). Youth (beta $=4.9,95 \%$ confidence interval $=3.3,6.5$ ) and caregivers ( $\operatorname{beta}=7.5,95 \%$ confidence interval $=3.1,12.0$ ) who rated their providers as being more participatory were significantly more satisfied with their visits. Youth (beta $=-1.9,95 \%$ confidence interval $=-3.4,-0.4$ ) and caregivers (beta $=-8.8,95 \%$ confidence interval $=-16.2,-1.3$ ) who spoke Spanish at home were less satisfied with visits.

Conclusion: The intervention did not increase the inclusion of youth and caregiver inputs into asthma treatment regimens. However, it did increase the youth's perception of participatory decision-making style of the providers, and this in turn was associated with greater satisfaction.

Keywords: shared decision-making, patient-provider, question prompt list, video intervention, communication, intervention

\section{Introduction}

Asthma is the most common chronic condition among US children. ${ }^{1,2}$ Little is known about the extent to which providers include youth and caregivers in asthma treatmentrelated decisions and how this is associated with visit satisfaction. ${ }^{3-6}$ Prior research in asthma found that caregivers were more satisfied with their children's providers if the patients reported that the providers used a more participatory style. ${ }^{4-6}$ In addition, other pediatric studies have reported that caregiver involvement in care is associated with 
caregiver satisfaction. ${ }^{7,8}$ One study found that very satisfied caregivers were more likely to state that they would visit the practice again and recommend it to others. ${ }^{9}$

Prior research evaluating on whether providers engage or involve families in shared decision-making (SDM) is limited. ${ }^{3,10-14}$ Cox et al $^{10}$ found that African-American families were significantly less likely to be actively engaged in decision making about respiratory conditions than the White families. They also found that $<2 \%$ of the families were engaged in treatment plans during visits. ${ }^{10}$ Other researchers examining communication during audiotaped visits found low levels of SDM during attention-deficit/hyperactivity disorder visits ${ }^{11,15}$ and during asthma visits. ${ }^{3}$ Yet caregivers reported high levels of SDM in other studies of the same medical conditions. ${ }^{4,13,14}$ It is, therefore, important to examine both caregiver and youth reports of SDM and whether SDM occurs during visits.

To encourage youth to be more actively involved during asthma visits, we created an asthma question prompt list and an educational video intervention. ${ }^{16,17}$ The intervention seeks to motivate adolescents to ask questions about asthma management to help them understand how to manage their asthma better after leaving the clinic visit. We conducted a randomized, controlled trial of the intervention and found that it significantly improved the youth's question-asking ability and provider education during asthma visits. ${ }^{18}$ However, it was unclear whether the intervention was associated with providers including youth and caregiver inputs into asthma management treatment decisions more often.

This study examined whether youth and caregivers who received the question prompt list and video intervention had their input included more often into asthma management treatment regimens and rated their providers as using more of a participatory decision-making (PDM) style. Specifically, we investigated whether 1) the providers included youth and caregiver inputs into the asthma management treatment regimen and 2) youth and caregiver ratings of their providers' use of a PDM style were associated with youth and caregiver satisfaction with their pediatric asthma visits.

\section{Methods}

\section{Procedure}

The study was approved by the University of North Carolina at Chapel Hill Institutional Review Board. Forty-six providers from four pediatric clinics (one academic and three private) in North Carolina agreed to participate in the study. Clinic staff briefly explained the study to all families attending an asthma visit whose children were aged between 11 and 17 years and had an asthma diagnosis. The clinic staff referred interested families to a research assistant to learn more about the study. During pre-visit wait time, the research assistant explained the study, obtained written informed consent and youth assent, and administered an eligibility screener. ${ }^{5,20}$

Children were eligible if they were aged between 11 and 17 years, spoke and read English or Spanish, had persistent asthma, were present for an acute or follow-up asthma visit or a well-child asthma visit, and had previously visited the clinic at least once for asthma. Persistent asthma was defined, based on the National Heart Lung and Blood Institute guidelines, as experiencing asthma-related daytime symptoms more than twice a week, asthma-related nighttime symptoms more than twice a month, or receiving one or more long-term controller therapies for asthma. ${ }^{19,24-26}$

The study statistician prepared the randomization envelopes for the research assistants to use. Adolescents were randomized within providers, and opaque envelopes were prepared for the research assistants at each site. Eligible youth were randomized to the intervention or usual care group. Youth in the intervention group watched the video with their caregivers on an iPad before their regularly scheduled clinic visit. ${ }^{16}$ Depending on the clinic, they watched the video either in a private area before the visit or with earphones in the waiting area. The youth then completed a one-page asthma question prompt list, in which they checked off the questions they wanted to ask their provider before their clinic visits. ${ }^{17}$ Clinic visits were audiotaped. All youth were interviewed after their medical visits by a research assistant while their caregivers completed a questionnaire. Both the youth and caregivers received $\$ 25$ each for their time.

\section{Measurement \\ Sociodemographics}

The age of the youth, the number of years the child has been living with asthma (reported by caregivers), caregivers' age, caregivers' years of education, and providers' age were considered as continuous variables. Gender of youth, caregivers, and providers was considered as dichotomous variable. The race of the youth was coded into five categories: non-Hispanic White, African-American, Native American/American Indian, Hispanic, or other. Race of caregivers and providers was recoded as dichotomous variable for the analysis (White and non-White). Asthma severity was classified as mild persistent versus moderate/severe persistent according to the National Heart Lung and Blood Institute's guidelines. 5,20,24,25 Caregivers reported how well they thought the providers knew their children: very well, moderately well, slightly, and hardly at 
all. Language spoken at home was measured as English or Spanish. Length of the visit was measured in minutes.

\section{Inclusion of youth and caregiver inputs by the providers into asthma treatment regimen plan}

All audiotapes of clinic visits were transcribed verbatim. Three research assistants were trained to code the transcripts using a detailed coding tool developed and used in prior asthma communication studies. ${ }^{27-29}$ The research assistants coded whether providers included youth input and caregiver input into the asthma management treatment regimen. An example of including child input would be, "We can either switch you to another medication or increase the dose of your existing inhaler, which do you prefer?" Three coders coded 34 of the same transcripts throughout the study period to assess interrater reliability. Inter-rater reliability was 1.0 if the provider included youth input and 1.0 if the provider included caregiver input into the asthma management treatment regimen.

\section{Youth and caregiver ratings of providers' PDM style}

Youth and caregiver ratings of providers' PDM style were measured using the three-item scale developed by Kaplan et al. ${ }^{30}$ The items were as follows: 1 ) "If there were a choice between treatments for your (your child's) asthma, would your provider ask you to help him/her make the decision?" (definitely yes $=5$, yes $=4$, unsure $=3$, no $=2$, definitely no $=1$ ), 2) "How often does your provider make an effort to give you some control over your (your child's) treatment?" (very often $=5$, often $=4$, sometimes $=3$, hardly at all $=2$, not at all $=1$, and 3) "How often does your provider ask you to take some of the responsibility for your (your child's) treatment?" (very often $=5$, often $=4$, sometimes $=3$, hardly at all $=2$, not at all $=1$ ). A summary score ranging from 0 to 100 was calculated by summing the responses, subtracting 3 , dividing it by 12 , and then multiplying by 100. Higher scores reflected youth and caregiver ratings of their providers as being more participatory. PDM style was then recoded into a dichotomous variable (score $<70$, score $\geq 70$ ). A cutoff point of 70 has been used in previous studies of provider use of a PDM style., 4,30,31

\section{Youth and caregiver satisfaction with visits}

Youth satisfaction was measured via interview and caregiver satisfaction was measured via survey after the audiotaped visits. A 12-item Child Satisfaction Questionnaire was used to measure provider-youth rapport and the youth's comfort with communication during the medical visit. ${ }^{32}$ The youth were asked to rate how often certain doctor behaviors occurred (e.g., the doctor explained things so I could remember them) and the response categories included never, not often, sometimes, often, and very often. Youth scores could range from 12 to 60 . The instrument has been validated for use in children aged 6-14 years and has a Cronbach's coefficient alpha of 0.89. Previous research demonstrates that the Child Satisfaction Questionnaire is significantly associated with children's descriptions of providers on an adjective checklist measure. ${ }^{32}$

Caregiver satisfaction was measured using the 26-item Caregiver Medical Interview Satisfaction Scale. Caregiver responses were on a 7-point Likert scale with $1=$ strongly disagree, $4=$ neutral, and $7=$ strongly agree. Caregiver scores could range from 26 to 182. Previous research has demonstrated that this scale is significantly associated with objective ratings of interpersonal skills of the providers during medical visits, and it has a Cronbach's coefficient alpha of $0.92 .{ }^{33-35}$

\section{Analysis}

All analyses were conducted using SPSS Version 24 (IBM Corporation, Armonk, NY, USA). We computed descriptive statistics for all variables. Race of youth was recoded as a dichotomous variable (white, non-white). We used generalized estimating equations (GEE) to examine how youth's gender, age, and race; years living with asthma; language spoken at home; asthma severity; whether the youth was in the intervention or usual care group; caregiver rating of how well the provider knows the child; and provider's age, gender, and race were associated with whether the child rated the provider as using a PDM style. We used GEE to examine how caregiver's age, race, and gender; years of education; years the child has had asthma; language spoken at home; child's asthma severity; whether the youth was in intervention or usual care group; caregiver rating of how well the provider knows the child; and provider's age, gender, and race were associated with whether the caregiver rated the child's provider as using a PDM style.

Next, we used GEE to examine how youth's gender, age, and race; years living with asthma; language spoken at home; asthma severity; whether the youth was in the intervention or usual care group; caregiver rating of how well the provider knows the child; provider's age, gender, and race; and provider's use of a PDM style were associated with youth satisfaction with their visit. Finally, we used GEE to predict how caregiver's age, race, and gender; years of education; years the child has had asthma; language spoken at home; 
child's asthma severity; whether the youth was in intervention or usual care group; caregiver rating of how well the provider knows the child; provider's age, gender, and race; and whether the caregiver rated the child's provider as using a PDM style were associated with caregiver satisfaction with the child's clinic visit.

\section{Results}

Forty-six providers agreed to participate in the study, and 40 of these providers enrolled patients. Participants were enrolled from June 2015 to November 2016. One hundred and ten participants did not meet the inclusion criteria. The main reasons for not meeting the inclusion criteria included the following: they had not been seen at the clinic before for asthma, no legal guardian present, and child did not have persistent asthma. Of the 412 eligible patients, 359 agreed to participate and 53 refused ( $87 \%$ participation rate). Table 1 presents the sociodemographic characteristics of the youth, caregivers, and providers.

When examining communication during visits, it was found that the providers included youth input into the asthma management treatment regimen only during nine visits $(2.5 \%)$. The intervention had no impact on whether the provider included youth input into the asthma treatment regimen: usual care group four times and intervention group five times. A total of $62 \%$ of youth rated their providers as high on using a participatory style for treatment decisions.

Providers included caregiver input into the asthma management treatment regimens only during 12 visits (3.3\%). The intervention had no impact on whether caregiver input was included in the asthma management treatment regimen: usual care group four times and intervention group eight times. A total of $72 \%$ of caregivers rated their children's providers as high on using a PDM style when making treatment decisions.

Table 2 presents the GEE results predicting youth and caregiver ratings of providers' PDM style. Youth in the intervention group (67\%) were significantly more likely to rate their providers as being more participatory (odds ratio $=1.7$, $95 \%$ confidence interval $=1.1,2.5)$ than the youth in the usual care group (57\%).

Factors increasing the likelihood of caregivers rating providers as being more participatory were White caregivers' racial identity (odds ratio $=2.3,95 \%$ confidence interval $=1.2$, 4.4), knowing their providers better (odds ratio $=2.5,95 \%$ confidence interval $=1.8,3.6$ ), and seeing female providers (odds ratio $=1.9,95 \%$ confidence interval $=1.1,3.5$ ), and younger providers (odds ratio $=0.96,95 \%$ confidence inter$\mathrm{val}=0.94,0.99$ ).
Table I Sociodemographic characteristics of the youth, caregivers, and providers ( $\mathrm{N}=359)$

\begin{tabular}{|c|c|}
\hline Characteristics & $\%(\mathbf{N})$ \\
\hline \multicolumn{2}{|l|}{ Youth gender } \\
\hline Male & $57.1(205)$ \\
\hline Female & $42.9(154)$ \\
\hline \multicolumn{2}{|l|}{ Youth race/ethnicity } \\
\hline Caucasian & $36.2(130)$ \\
\hline African-American & $37.2(134)$ \\
\hline Hispanic & $12.5(45)$ \\
\hline Native American & II.4 (4I) \\
\hline Other & $2.5(9)$ \\
\hline \multicolumn{2}{|l|}{ Asthma severity } \\
\hline Mild & $46.8(168)$ \\
\hline Moderate/severe & $53.2(191)$ \\
\hline \multicolumn{2}{|l|}{ Language spoken at home } \\
\hline English & $91.4(328)$ \\
\hline Spanish & $8.6(3 I)$ \\
\hline \multicolumn{2}{|l|}{ Caregiver gender } \\
\hline Male & $13.6(49)$ \\
\hline Female & $86.4(310)$ \\
\hline \multicolumn{2}{|l|}{ Caregiver race } \\
\hline Caucasian & $46.0(165)$ \\
\hline Non-Caucasian & $54.0(194)$ \\
\hline \multicolumn{2}{|c|}{ How well caregiver reports that the } \\
\hline \multicolumn{2}{|c|}{ provider knows the child } \\
\hline Very well & $58.5(21)$ \\
\hline Moderately well & $29.2(105)$ \\
\hline Slightly & $9.5(34)$ \\
\hline Hardly at all & $2.8(10)$ \\
\hline \multicolumn{2}{|l|}{ Provider gender } \\
\hline Male & $32.9(118)$ \\
\hline Female & $67.1(24 I)$ \\
\hline \multicolumn{2}{|l|}{ Provider race } \\
\hline White & $73.0(262)$ \\
\hline \multirow[t]{2}{*}{ Non-White } & $27.0(97)$ \\
\hline & Mean (SD), range \\
\hline Youth age & $13.2(1.9), 11-17$ \\
\hline Years living with asthma & $9.5(4.1), 1-17$ \\
\hline Caregiver age & $42.6(8.6), 19-76$ \\
\hline Caregiver education (in years) & $13.6(3.3), 4-26$ \\
\hline Provider age & 44.1 (II.4), 28-62 \\
\hline
\end{tabular}

Abbreviation: SD, standard deviation.

Table 3 presents the GEE predicting youth and caregiver satisfaction with their visits. Youth who rated their providers as being more participatory were significantly more satisfied with their visits (beta $=4.9,95 \%$ confidence interval $=3.3,6.5$ ). Youth were less satisfied with visits with older providers (beta $=-0.06,95 \%$ confidence interval $=-0.11,-0.01$ ). Youth who spoke Spanish at home were less satisfied with visits than youth who spoke English at home (beta $=-1.9,95 \%$ confidence interval $=-3.4,-0.4$ ).

Caregivers who rated their children's providers as being more participatory were significantly more satisfied with 
Table 2 Generalized estimating equations predicting youth and caregiver ratings of provider use of a participatory decisionmaking style $(\mathrm{N}=359)$

\begin{tabular}{|c|c|}
\hline $\begin{array}{l}\text { Youth rating of providers' participatory } \\
\text { decision-making style }\end{array}$ & $\begin{array}{l}\text { Odds ratio } \\
\text { ( } 95 \% \text { confidence } \\
\text { interval) }\end{array}$ \\
\hline \multicolumn{2}{|l|}{ Independent variables } \\
\hline Youth gender - male & $1.5(0.9,2.5)$ \\
\hline Youth age & $0.9(0.8,1.0)$ \\
\hline Youth race - White & I.I $(0.7,1.7)$ \\
\hline Asthma severity - moderate/severe & $1.4(0.9,2.1)$ \\
\hline Years living with asthma & $0.9(0.8,1.0)$ \\
\hline Language spoken at home - Spanish & $0.8(0.4,1.6)$ \\
\hline $\begin{array}{l}\text { Whether youth was in intervention or usual } \\
\text { care group }\end{array}$ & $1.7(1.1,2.5)^{*}$ \\
\hline $\begin{array}{l}\text { Caregiver rating of how well the provider } \\
\text { knows the child }\end{array}$ & $0.8(0.6,1.0)$ \\
\hline Provider age & $1.0(0.9,1.1)$ \\
\hline Provider race - White & $0.8(0.5,1.4)$ \\
\hline Provider gender - female & $0.8(0.5,1.5)$ \\
\hline \multicolumn{2}{|l|}{ Caregiver rating of provider's } \\
\hline \multicolumn{2}{|l|}{ participatory decision-making style } \\
\hline \multicolumn{2}{|l|}{ Independent variables } \\
\hline Caregiver age & $1.0(0.9, \mathrm{I} . \mathrm{I})$ \\
\hline Caregiver race - White & $2.3(1.2,4.4)^{* *}$ \\
\hline Caregiver gender & I.3 $(0.7,2.3)$ \\
\hline Caregiver education (in years) & $0.9(0.8,1.0)$ \\
\hline Asthma severity - moderate/severe & $1.0(0.6,1.8)$ \\
\hline Years living with asthma & $1.0(0.9,1.1)$ \\
\hline Language spoken at home - Spanish & $0.7(0.3,1.6)$ \\
\hline $\begin{array}{l}\text { Whether youth was in intervention or usual } \\
\text { care group }\end{array}$ & $1.3(0.7,2.4)$ \\
\hline Caregiver rating of how well the provider & $2.5(1.8,3.6)^{* * *}$ \\
\hline \multicolumn{2}{|l|}{ knows the child } \\
\hline Provider age & $0.96(0.94,0.99)^{*}$ \\
\hline Provider race - White & $0.6(0.3,1.3)$ \\
\hline Provider gender - female & $1.9(1.1,3.5)^{*}$ \\
\hline
\end{tabular}

Notes: $* p<0.05, * * p<0.01, * * * p<0.001$.

their visits (beta $=7.5,95 \%$ confidence interval=3.1, 12.0). Caregivers were significantly more satisfied with visits when they rated the providers as knowing their children better (beta $=3.7,95 \%$ confidence interval $=1.5,5.8$ ). Caregivers who spoke Spanish at home were significantly less satisfied with visits than caregivers who spoke English at home (beta $=-8.7$, $95 \%$ confidence interval $=-16.2,-1.3)$.

\section{Discussion}

Using the recordings of patient-provider encounters, this study found that providers rarely included youth or caregiver input into the asthma management treatment regimens, $2.5 \%$ and $3.3 \%$ of visits, respectively. Although our intervention significantly increased the child's question-asking and provider education about asthma and its treatment, ${ }^{18}$ it did not
Table 3 Generalized estimating equations predicting youth and caregiver satisfaction with visits $(\mathrm{N}=359)$

\begin{tabular}{|c|c|}
\hline Youth satisfaction with visit & $\begin{array}{l}\text { Beta }(95 \% \\
\text { confidence } \\
\text { interval) }\end{array}$ \\
\hline \multicolumn{2}{|l|}{ Independent variables } \\
\hline Youth gender - male & $0.1(-1.0,1.2)$ \\
\hline Youth age & $0.1(-0.2,0.4)$ \\
\hline Youth race - White & $-0.6(-1.7,0.5)$ \\
\hline $\begin{array}{l}\text { Youth rating of provider's participatory } \\
\text { decision-making style }\end{array}$ & $4.9(3.3,6.5)^{* * *}$ \\
\hline Asthma severity - moderate/severe & $-0.1(-1.7,1.7)$ \\
\hline Language spoken at home - Spanish & $-1.9(-3.4,-0.4)^{*}$ \\
\hline Years living with asthma & $0.3(-0.9,1.5)$ \\
\hline $\begin{array}{l}\text { Whether youth was in intervention or usual } \\
\text { care group }\end{array}$ & $0.3(-0.9,1.5)$ \\
\hline $\begin{array}{l}\text { Caregiver rating of how well the provider } \\
\text { knows the child }\end{array}$ & $1.0(-0.2,2.3)$ \\
\hline Provider age & $-0.06(-0.1 \mathrm{I},-0.0 \mathrm{I})^{*}$ \\
\hline Provider race - White & $-0.8(-2.4,0.9)$ \\
\hline Provider gender - female & $0.9(-0.3,2.2)$ \\
\hline \multicolumn{2}{|l|}{ Caregiver satisfaction with visit } \\
\hline \multicolumn{2}{|l|}{ Independent variables } \\
\hline Caregiver age & $-0.1(-0.2,0.1)$ \\
\hline Caregiver race - White & $0.3(-2.5,3.1)$ \\
\hline Caregiver gender & $3.4(-8.5,1.7)$ \\
\hline Caregiver education (in years) & $-0.04(-0.5,0.4)$ \\
\hline $\begin{array}{l}\text { Caregiver rating of provider's participatory } \\
\text { decision-making style }\end{array}$ & $7.5(3.1,12.0)^{* *}$ \\
\hline Asthma severity - moderate/severe & $-2.3(-4.9,0.3)$ \\
\hline Language spoken at home - Spanish & $-8.7(-16.2,-1.3)^{*}$ \\
\hline Years living with asthma & $-0.3(-0.7,0.1)$ \\
\hline $\begin{array}{l}\text { Whether youth was in intervention or usual } \\
\text { care group }\end{array}$ & $-1.8(-4.1,0.5)$ \\
\hline $\begin{array}{l}\text { Caregiver rating of how well the provider } \\
\text { knows the child }\end{array}$ & $3.7(1.5,5.8)^{* * *}$ \\
\hline Provider age & $0.1(-0.5,0.3)$ \\
\hline Provider race - White & $1.0(-2.6,4.5)$ \\
\hline Provider gender - female & $-1.1(-4.8,2.7)$ \\
\hline
\end{tabular}

Notes: ${ }^{*} p<0.05,{ }^{*} p<0.01, *^{*} * *_{p}<0.001$.

increase the frequency with which providers included youth or caregiver input into treatment regimens. Future research should design and test other ways to increase youth and caregiver inputs into asthma treatment regimens, particularly when there is a treatment decision to be made involving more than one reasonable treatment option. Including youth and caregiver inputs into asthma decisions could potentially lead to better youth health outcomes. ${ }^{3,19-23}$

Despite providers rarely including youth or caregiver input into the asthma management treatment regimen, youth and caregivers tend to rate providers favorably in terms of PDM. Our findings are similar to prior studies, which have found that when observing actual communication, SDM does not occur often during pediatric visits. ${ }^{3,11,12}$ Yet, even when 
objective ratings indicate that SDM did not occur, caregivers still tend to report high rates of SDM. ${ }^{4,13,14}$ The reasons for the discrepancy between perceived PDM style as reported by youth and caregivers and explicit inclusion in treatment decisions as observed in audio recordings are unclear. One reason may be that expectations among youth and caregivers about actual participation in treatment decisions are low, and thus, their perceived participation can easily exceed these low expectations. Another reason may be that when our study participants reported the degree of PDM style that their providers used, they may be answering based on aggregate experiences from previous visits or based on a favorable impression of, or relationship with, their provider rather than referring to the specific discussion at that visit. This explanation is supported by our finding that if caregivers reported that the providers knew their children better, they were significantly more likely to rate the providers as having a PDM style. Future research should investigate what factors influence youth and caregiver ratings of providers' PDM style.

We also found that youth in the intervention group were more likely to rate their providers as using more of a PDM style than youth in the usual care group. The effectiveness of the intervention on this outcome may be due, at least in part, to the fact that youth in the intervention arm asked more questions of providers and received more provider explanations and education about asthma than those in the control arm. ${ }^{18}$ This improved patient-provider communication likely played a role in how youth perceived their providers' decision-making style, even in the absence of direct input into treatment decisions.

In this analysis, we also found that caregivers rated younger and female providers as using more of a PDM style. Also, White caregivers were more likely to rate their providers as using more of a PDM style than non-White caregivers. This finding is similar to prior research studies, which have found that SDM occurred more in White families than nonWhite families. ${ }^{10,11}$ Future research should investigate why this disparity exists and what can be done to improve SDM with non-White families.

Caregivers in our study reported greater satisfaction with providers who were rated as using more of a PDM style during clinic visits, which is similar to the results of prior research. ${ }^{4-6}$ Youth were also significantly more satisfied with providers who they rated as using more of a PDM style. Providers should strive to use a PDM style with youth and their caregivers. They could present treatment options to families and then ask both youth and caregivers questions such as "What treatment would you prefer to use for your asthma?" This would allow caregivers to give more input into how they would like to manage their children's asthma. Likewise, this will empower youth to manage their own asthma and may improve adherence.

We found that both youth and caregivers who spoke Spanish at home were significantly less satisfied with visits than those who spoke English at home. This is consistent with previous studies, which have also found lower satisfaction with both quality of communication and the overall visit when Spanish-speaking youth saw non-Spanish-speaking providers. ${ }^{36-39}$ A national survey of US pediatricians found that they most often rely on untrained interpreters, including family members, to communicate when a patient or caregiver does not speak English. ${ }^{40}$ Experts have suggested that requiring third-party reimbursement for professional language services may increase the use of trained interpreters and quality of care. ${ }^{41}$ Pediatric practitioners need to be cognizant of potential communication barriers and work closely with Spanish-speaking families to develop methods to improve communication and satisfaction in clinic visits.

Our study has limitations. First, it was conducted in four pediatric practices in North Carolina, and the results may not be generalizable to other regions or practice types. Second, the analysis of audiotape encounters examined only one element of SDM about asthma management, that is, whether the providers included youth and caregiver inputs into the asthma treatment plan. There are likely other aspects of provider behavior that are relevant to patient-centered asthma care and that affect perceived PDM style and visit satisfaction. Third, our measure of youth's and caregivers' perception of providers' PDM style may reflect their relationship with the providers over time and not the providers' behavior at one visit, as noted above. Finally, we were able to measure and compare only two levels of asthma disease severity, mild persistent versus moderate-to-severe persistent asthma, and were unable to breakdown the moderate-to-severe group further. Despite the limitations of the study, it provides new evidence regarding the effects of a patient-directed intervention involving a question prompt list and video on youth and caregiver perceptions of provider PDM style, provider inclusion of youth and caregiver inputs into asthma management treatment regimens, and satisfaction with visits.

\section{Conclusion}

In summary, our findings suggest that providers rarely include youth and caregiver inputs into asthma treatment regimens and that this is not improved by a question prompt list and video intervention. Despite this, our results also suggest that youth and caregivers perceive many providers as hav- 
ing high PDM styles and that our intervention increases this favorable perception among youth. We found that youth and caregivers were more satisfied with providers who were rated as using more of a PDM style. Further research is needed to study how such interventions can be implemented in clinical practice and to further understand barriers to providers' use of SDM about asthma treatment. The reasons for the discrepancy between PDM as reported by patients and caregivers, compared with when it is directly observed (using audio recording), are unclear. One reason may be that when caregivers and youth report on how much of a PDM style their providers use, they may be answering based on collective experiences from previous visits or based on an overall favorable impression of or relationship with their providers rather than recalling specific discussions with the providers.

\section{Acknowledgments}

This work was supported through a Patient-Centered Outcomes Research Institute (PCORI) Program Award (140209777). Drs. Sleath and Reuland are also supported by the National Center for Advancing Translational Sciences (NCATS), National Institutes of Health, through Grant Award Number 1UL1TR001111.

\section{Disclosure}

The authors report no conflicts of interest in this work.

\section{References}

1. National Academy on an Aging Society. Childhood asthma: the most common chronic disease among children. Challenges for the 21st Century: Chronic and Disabling Conditions. June 2000; Number 8. Available from: http://www.civicengagement.org/agingsociety/pdf/ asthma.pdf. Accessed March 12, 2018.

2. Centers for Disease Control and Prevention. Vital signs: asthma prevalence, disease characteristics, and self-management education: United States, 2001-2009. MMWR Morb Mortal Wkly Rep. 2011;60(17):547-552.

3. Sleath BL, Carpenter DM, Sayner R, et al. Child and caregiver involvement and shared decision-making during asthma pediatric visits. J Asthma. 2011;48(10):1022-1031.

4. Sleath B, Ayala GX, Washington D, et al. Caregiver rating of provider participatory decision-making style and caregiver and child satisfaction with pediatric asthma visits. Patient Educ Couns. 2011;85(2):286-289.

5. Wissow LS, Roter D, Bauman LJ, et al. Patient-provider communication during the emergency department care of children with asthma. The National Cooperative Inner-City Asthma Study, National Institute of Allergy and Infectious Diseases, NIH, Bethesda, MD. Med Care. 1998;36(10):1439-1450.

6. Clark NM, Cabana MD, Nan B, et al. The clinician-patient partnership paradigm: outcomes associated with physician communication behavior. Clin Pediatr (Phila). 2008;47(1):49-57.

7. October TW, Hinds PS, Wang J, Dizon ZB, Cheng YI, Roter DL. Parent satisfaction with communication is associated with physician's patientcentered communication patterns during family conferences. Pediatr Crit Care Med. 2016;17(6):490-497.
8. Matziou V, Boutopoulou B, Chrysostomou A, Vlachioti E, Mantziou T, Petsios K. Parents' satisfaction concerning their child's hospital care. Jpn J Nurs Sci. 2011;8(2):163-173.

9. Weissenstein A, Straeter A, Villalon G, Luchter E, Bittmann S. Parent satisfaction with a pediatric practice in germany: a questionnaire-based study. Ital J Pediatr. 2011;37:31.

10. Cox ED, Nackers KA, Young HN, Moreno MA, Levy JF, MangioneSmith RM. Influence of race and socioeconomic status on engagement in pediatric primary care. Patient Educ Couns. 2012;87(3):319-326.

11. Brinkman WB, Hartl J, Rawe LM, Sucharew H, Britto MT, Epstein JN. Physicians' shared decision-making behaviors in attentiondeficit/hyperactivity disorder care. Arch Pediatr Adolesc Med. 2011;165(11):1013-1019.

12. Brinkman WB, Hartl Majcher J, Poling LM, et al. Shared decisionmaking to improve attention-deficit hyperactivity disorder care. Patient Educ Couns. 2013;93(1):95-101.

13. Fiks AG, Localio AR, Alessandrini EA, Asch DA, Guevara JP. Shared decision-making in pediatrics: a national perspective. Pediatrics. 2010;126(2):306-314.

14. Toomey SL, Homer CJ, Finkelstein JA. Comparing medical homes for children with ADHD and asthma. Acad Pediatr. 2010;10(1):56-63.

15. Sleath B, Sulzer SH, Carpenter DM, et al. Communication about ADHD and its treatment during pediatric asthma visits. Community Ment Health J. 2014;50(2):185-192.

16. Sleath B, Carpenter DM, Lee C, et al. The development of an educational video to motivate teens with asthma to be more involved during medical visits and to improve medication adherence. J Asthma. 2016;53(7):714-719.

17. Sleath B, Carpenter DM, Davis SA, et al. Acceptance of a pre-visit intervention to engage teens in pediatric asthma visits. Patient Educ Couns. 2017;100(11):2005-2011.

18. Sleath B, Carpenter DM, Davis SA, et al. Improving youth questionasking and provider education during pediatric asthma visits. Patient Educ Couns. EPub 2018 Feb 15.

19. Sleath B, Carpenter DM, Slota C, et al. Communication during pediatric asthma visits and self-reported asthma medication adherence. Pediatrics. 2012;130(4):627-633.

20. Tates K, Meeuwesen L. Doctor-parent-child communication. A (re) view of the literature. Soc Sci Med. 2001;52(6):839-851.

21. Harrington J, Noble LM, Newman SP. Improving patients' communication with doctors: a systematic review of intervention studies. Patient Educ Couns. 2004;52(1):7-16.

22. Roter D. The medical visit context of treatment decision-making and the therapeutic relationship. Health Expect. 2000;3(1):17-25.

23. Hall JA, Roter DL, Katz NR. Meta-analysis of correlates of provider behavior in medical encounters. Med Care. 1988;26(7):657-675.

24. National Heart Lung and Blood Institute. National heart lung and blood institute publication number 97-4051. Guidelines for the Diagnosis and Management of Asthma. Expert panel report 2; 1997. Available from: http://www.nhlbi.nih.gov/files/docs/guidelines/asthgdln_archive.pdf. Accessed December 1, 2017.

25. National Heart Lung and Blood Institute. National heart lung and blood institute publication number 08-5846. Guidelines for the Diagnosis and Management of Asthma. Expert panel report 3; 2007. Available from: http://www.nhlbi.nih.gov/files/docs/guidelines/asthsumm.pdf. Accessed December 1, 2017.

26. Sleath B, Ayala GX, Gillette C, et al. Provider demonstration and assessment of child device technique during pediatric asthma visits. Pediatrics. 2011;127(4):642-648.

27. O'Neill KA. Kids speak: effective communication with the school-aged/ adolescent patient. Pediatr Emerg Care. 2002;18(2):137-140.

28. Street RL Jr, Makoul G, Arora NK, Epstein RM. How does communication heal? Pathways linking clinician-patient communication to health outcomes. Patient Educ Couns. 2009;74(3):295-301.

29. Street RL Jr. How clinician-patient communication contributes to health improvement: modeling pathways from talk to outcome. Patient Educ Couns. 2013;92(3):286-291. 
30. Kaplan SH, Gandek B, Greenfield S, Rogers W, Ware JE. Patient and visit characteristics related to physicians' participatory decisionmaking style. Results from the medical outcomes study. Med Care. 1995;33(12):1176-1187.

31. Honeycutt C, Sleath B, Bush PJ, Campbell W, Tudor G. Physician use of a participatory decision-making style with children with ADHD and their parents. Patient Educ Couns. 2005;57(3):327-332.

32. Rifkin L, Wolf MH, Lewis CC, Pantell RH. Children's perceptions of physicians and medical care: two measures. J Pediatr Psychol. 1988;13(2):247-254.

33. Bernzweig J, Takayama JI, Phibbs C, Lewis C, Pantell RH. Gender differences in physician-patient communication. Evidence from pediatric visits. Arch Pediatr Adolesc Med. 1997;151(6):586-591.

34. Lewis CC, Scott DE, Pantell RH, Wolf MH. Parent satisfaction with children's medical care. Development, field test, and validation of a questionnaire. Med Care. 1986;24(3):209-215.

35. Lewis CC, Pantell RH, Sharp L. Increasing patient knowledge, satisfaction, and involvement: randomized trial of a communication intervention. Pediatrics. 1991;88(2):351-358.
36. Dunlap JL, Jaramillo JD, Koppolu R, Wright R, Mendoza F, Bruzoni $M$. The effects of language concordant care on patient satisfaction and clinical understanding for hispanic pediatric surgery patients. $J$ Pediatr Surg. 2015;50(9):1586-1589.

37. Flower KB, Skinner AC, Yin HS, et al. Satisfaction with communication in primary care for Spanish-speaking and English-speaking parents. Acad Pediatr. 2017;17(4):416-423.

38. Halfon N, Inkelas M, Mistry R, Olson LM. Satisfaction with health care for young children. Pediatrics. 2004;113(6 Suppl): 1965-1972.

39. Jaramillo J, Snyder E, Dunlap JL, Wright R, Mendoza F, Bruzoni M. The hispanic clinic for pediatric surgery: a model to improve parent-provider communication for hispanic pediatric surgery patients. J Pediatr Surg. 2016;51(4):670-674.

40. Kuo DZ, O’Connor KG, Flores G, Minkovitz CS. Pediatricians' use of language services for families with limited english proficiency. Pediatrics. 2007;119(4):e920-e927.

41. $\mathrm{Ku} \mathrm{L}$, Flores $\mathrm{G}$. Pay now or pay later: providing interpreter services in health care. Health Aff (Millwood). 2005;24(2):435-444.

\section{Patient Related Outcome Measures}

\section{Publish your work in this journal}

Patient Related Outcome Measures is an international, peer-reviewed, open access journal focusing on treatment outcomes specifically relevant to patients. All aspects of patient care are addressed within the journal and practitioners from all disciplines are invited to submit their work as well as healthcare researchers and patient support groups.

\section{Dovepress}

The journal is included in PubMed. The manuscript management system is completely online and includes a very quick and fair peer-review system. Visit http://www.dovepress.com/testimonials.php to read real quotes from published authors. 